\title{
Evaluasi Perencanaan Persediaan Antibiotik Secara Kuantitatif di Instalasi Farmasi Rumah Sakit Tipe A
}

\author{
Quantitative Evaluation of Antibiotics Inventory Planning in Type A Hospital's Pharmacy Department
}

\author{
Venna Laurensia ${ }^{1}$, Gusti Noorrizka Veronika Achmad², Raswita Diniya ${ }^{3}$, Ivonne Soeliono ${ }^{1 *}$ \\ 1. Fakultas Farmasi, Universitas Katolik Widya Mandala, Surabaya, Indonesia \\ 2. Universitas Airlangga, Surabaya, Indonesia \\ 3. Rumah Sakit Tipe A, Surabaya, Indonesia \\ Submitted: 12-11-2019 Revised: 29-05-2020 \\ Accepted: 28-09-2020
}

Korespondensi : Ivonne Soeliono : Email : ivonne-s@ukwms.ac.id

\begin{abstract}
ABSTRAK
Perencanaan persediaan antibiotik yang tidak baik akan menyebabkan terjadinya masalah dalam perencanaan yaitu adanya kelebihan stok antibiotik (stagnant) dan kekurangan stok antibiotik (stockout). Pada penelitian ini dilakukan evaluasi persediaan antibiotik secara kuantitatif dengan menggunakan metode Economic Order Quantity (EOQ) dan Maximum-Minimum Stock Level (MMSL) berdasarkan data penggunaan antibiotik tahun 2017 di Instalasi Farmasi Rumah Sakit tipe A di Indonesia. Metode EOQ bertujuan untuk meminimalkan jumlah pesanan sedangkan metode MMSL digunakan untuk menentukan stok minimum dan stok maksimum antibiotik yang harus dipesan. Hasil tersebut dibandingkan dengan kebutuhan pada tahun 2018 kemudian dilakukan perhitungan untuk menentukan jumlah antibiotik yang stagnant dan stockout. Jumlah antibiotik yang stagnant dengan simulasi metode EOQ adalah 44,73\% dan dengan metode MMSL 48,02\%, sedangkan jumlah antibiotik yang stockout dengan metode EOQ yaitu $38,15 \%$ dan dengan metode MMSL 42,76\%. Kategori persediaan antibiotik pada tahun 2018 secara riil yang termasuk dalam keadaan stagnant adalah 23,68\%, stockout yaitu 55,26\% dari 152 antibiotik. Hasil evaluasi perencanaan persediaan antibiotik dengan metode EOQ dan MMSL dapat mengurangi jumlah antibiotik stockout tetapi tidak mengurangi antibiotik stagnant. Diperlukan penelitian lebih lanjut dengan mengikutsertakan seluruh jenis obat dan alat kesehatan yang ada di Instalasi Farmasi untuk dapat menentukan evaluasi perencanaan dengan metode pengendalian persediaan perbekalan farmasi yang paling sesuai untuk rumah sakit tipe A di Indonesia.
\end{abstract}

Kata kunci: Evaluasi perencanaan; EOQ; MMSL; stagnant; stockout

\section{ABSTRACT}

Planning an inventory of antibiotics that are not good will cause problems in planning, which are over-supply of antibiotics (stagnant) and lack of antibiotic stock (stockout). In this study a quantitative evaluation of antibiotic inventory planning was carried out using the Economic Order Quantity (EOQ) and Maximum-Minimum Stock Level (MMSL) control methods in 2017 at Type A Hospital's Pharmacy Department. The EOQ method aims to minimize the number of orders while the MMSL method is used to determine the minimum and maximum stock of antibiotics that must be ordered. The results were compared with the need for 2018 then calculations are carried out to determine the amount of stagnant and stockout antibiotics. The number of antibiotics that were stagnant by EOQ method simulation was $44.73 \%$ and by MMSL method was $48.02 \%$, while the number of antibiotics stocked by EOQ method was $38.15 \%$ and by MMSL method was $42.76 \%$. The category of antibiotic supplies in 2018 in real terms which was included in a stagnant state was $23.68 \%$, stockout i.e. $55.26 \%$ of 152 antibiotics. Evaluation of antibiotic inventory planning using the EOQ method results in the calculation of lower order quantities while the number of orders with MMSL is higher. To find out more broadly about the evaluation of inventory planning in the hospital needed further research by taking into account all drugs not just antibiotics.

Keywords: Planning Evaluation; EOQ; MMSL; stagnant; stockout

\section{PENDAHULUAN}

Antibiotik sangat banyak digunakan dalam pengobatan infeksi di dalam rumah sakit. Penggunaan antibiotik sangat ditunjang dengan ketersediaan antibiotik di rumah sakit, terutama karena rumah sakit dalam penelitian ini merupakan rumah sakit kelas A yang permintaan penggunaan antibiotiknya sangat 
tinggi. Jumlah persediaan antibiotik yang tidak mencukupi kebutuhan persediaan dapat menjadi salah satu penyebab terjadinya resistensi antibiotik pada pasien.

Perencanaan merupakan dasar tindakan untuk menentukan kebutuhan yang diperlukan untuk periode yang akan datang. Perencanaan sangat penting dilakukan untuk menjamin terpenuhinya kriteria tepat jenis, tepat jumlah, tepat waktu dan efisien ${ }^{1}$. Faktor yang mempengaruhi perencanaan obat adalah epidemiologi penyakit, efektivitas obat terhadap penyakit dan harga obat². Tujuan dari perencanaan adalah untuk mendapatkan jenis dan jumlah antibiotik sesuai kebutuhan pelayanan serta untuk meningkatkan penggunaan antibiotik secara rasional. Perencanaan persediaan yang baik akan menghindari terjadinya masalah yang menyebabkan tidak efisiennya pemanfaatan antibiotik di rumah sakit.

Masalah yang sering terjadi dalam perencanaan persediaan adalah kelebihan persediaan obat (stagnant) dan kekurangan persediaan obat (stockout) ${ }^{3}$. Obat stagnant adalah sisa obat pada akhir bulan lebih dari tiga kali rata-rata pemakaian obat per bulan. Stockout adalah keadaan ketika jumlah sisa persediaan kurang dari pemakaian rata-rata ${ }^{4}$.

Evaluasi perencanaan persediaan dilakukan dengan menggunakan metode pengendalian agar perencanaan yang diadakan dapat optimal ${ }^{5}$. Penelitian ini menggunakan metode pengendalian persediaan secara kuantitatif yaitu EOQ (Economic Order Quantity) dan MMSL (Maximum-Minimum Stock Level). Metode EOQ memerlukan dua jenis biaya yang untuk perhitungan yaitu biaya pemesanan (ordering cost) dan biaya penyimpanan (holding cost). Biaya penyimpanan (holding cost) adalah biaya yang dikeluarkan yang berhubungan dengan diadakannya persediaan barang yaitu biaya listrik (lampu, kulkas, AC) dan biaya sumber daya manusia ${ }^{5}$. Biaya pemesanan adalah biaya setiap kali dilakukan pemesanan obat antara lain biaya telepon, biaya administrasi dan biaya sumber daya manusia. Metode MMSL menentukan stok minimum dan stok maksimum persediaan dengan memperhatikan lead time, consumption average, safety stock dan periode pengadaan.

State of the art dari penelitian ini yaitu menghitung persediaan farmasi yang diperlukan serta memperhitungkan jumlah obat yang termasuk dalam kategori persediaan stagnant maupun stockout berdasarkan metode EOQ dan MMSL. Pada penelitian sebelumnya ${ }^{6}$, metode EOQ dan MMSL hanya digunakan untuk menghitung persediaan farmasi yang diperlukan namun tidak memperhitungkan jumlah obat yang stagnant dan stockout. Selain itu, terdapat penelitian lain dimana dilakukan penentuan faktor penyebab stagnant dan stockout namun tidak menggunakan metode EOQ dan MMSL (Mellen pudjirahardjo) sehingga diharapkan penelitian ini memberi gambaran yang lebih jelas mengenai obat yang stagnant dan stockout yang didapatkan dari perhitungan metode EOQ dan MMSL.

Tidak adanya perhitungan jumlah obat stagnant dan stockout dapat menyulitkan tenaga kesehatan dalam melakukan pengadaan sediaan farmasi untuk periode selanjutnya. Oleh karena itu, dilakukan evaluasi perencanaan persediaan antibiotik di Instalasi Farmasi Rumah Sakit tipe A dengan menggunakan metode pengendalian persediaan EOQ dan MMSL untuk menentukan jumlah pengendalian persediaan pada tahun 2017 dan 2018 serta untuk mengetahui pendistribusian antibiotik dan untuk mengetahui adanya stagnant dan stockout persediaan sehingga dapat digunakan sebagai pertimbangan perencanaan antibiotik selanjutnya di rumah sakit.

\section{METODE}

Jenis penelitian yang dilakukan adalah studi observasional dan pengambilan data dilakukan secara retrospektif pada tahun 2017 dan 2018. Penelitian ini hanya dilakukan pada satu rumah sakit tipe A di Indonesia dan dilakukan dengan menggunakan kartu stok pada semua sampel antibiotika di Gudang Instalasi Farmasi Rumah Sakit. Penelitian mengenai evaluasi perencanaan persediaan 
antibiotik dilakukan secara kuantitatif dengan menggunakan metode pengendalian persediaan EOQ dan MMSL. Kriteria inklusi pada penelitian ini adalah antibiotik yang tercatat keluar dari gudang IFRS baik pada bulan Januari-Desember 2017 maupun pada bulan Januari-Desember 2018 sedangkan kriteria eksklusi pada penelitian ini adalah data pengeluaran antibiotik yang tidak lengkap.

Perhitungan pengendalian persediaan antibiotik pada tahun 2017 dan 2018 dengan metode EOQ dihitung dengan menggunakan rumus:

$$
\mathrm{EOQ}=\sqrt{\frac{2 D S}{H}}
$$

Keterangan: EOQ : jumlah pemesanan yang meminimalkan biaya persediaan; $\mathrm{D}=$ jumlah kebutuhan barang (unit/tahun); $\mathrm{S}=$ biaya pemesanan yang ditentukan dari kuantitas pemesanan; $\mathrm{H}=$ biaya penyimpanan dengan satuan rupiah/unit/tahun

Perhitungan pengendalian persediaan antibiotik pada tahun 2017 dan 2018 dengan metode MMSL dihitung dengan menggunakan rumus :

$$
\begin{aligned}
& \text { Smin }=(\mathrm{LT} \times \mathrm{CA})+\mathrm{SS}=2 \mathrm{SS} \\
& \text { Smaks }=\mathrm{Smin}+(\mathrm{PP} \times \mathrm{CA})
\end{aligned}
$$

Keterangan: Smin $=$ stok minimal; Smaks $=$ stok maksimum; $\mathrm{CA}=$ consumption average atau rata-rata pemakaian setiap bulan; $\mathrm{LT}=$ lead time; $\mathrm{PP}=$ periode pengadaan; $\mathrm{SS}=$ safety stock atau stok pengaman (LT x CA)

Kemudian dilakukan perhitungan jumlah antibiotik yang masuk dalam kategori stagnant dan stockout pada tahun 2018 baik keadaan riil maupun dengan metode EOQ dan MMSL. Untuk menentukan kategori persediaan antibiotik, maka harus dilakukan perhitungan sisa stok pada setiap metode. Sisa stok pada metode EOQ dapat dihitung dengan rumus :

Sisa stok $=($ pembelian EOQ $\mathrm{x}$ frekuensi pembelian $)+$ stok awal - pemakaian(tahun)

Keterangan: Pembelian EOQ = jumlah pemesanan yang dihitung dengan metode EOQ tahun 2017; Frekuensi pembelian = $\frac{\text { pemakaian (tahun) }}{\text { pembelian EOQ }}$ Stok awal = stok awal pada bulan Januari tahun 2018; Pemakaian (tahun) = jumlah pemakaian antibiotik selama 1 tahun

Sisa stok pada metode MMSL dapat dihitung dengan rumus :

Sisa stok $=($ pembelian MMSL $\mathrm{x}$ frekuensi pembelian $)+$ stok awal - pemakaian(tahun)

Keterangan: Pembelian MMSL = jumlah pemesanan yang dihitung dengan metode MMSL tahun 2017; Frekuensi pembelian = jumlah pengadaan dalam 1 tahun (dapat diketahui dari periode pengadaan); Stok awal = stok awal pada bulan Januari tahun 2018; Pemakaian (tahun) $=$ jumlah pemakaian antibiotik selama 1 tahun

Setelah diketahui sisa stok dengan masing-masing metode, maka dapat ditentukan kategori persediaan antibiotik dengan melihat sisa stok dengan pemakaian rata-rata per bulan. Antibiotik dikatakan stagnant bila sisa stok lebih dari tiga kali pemakaian rata-rata per bulan sedangkan antibiotik yang dikatakan stockout bila sisa stok kurang dari pemakaian rata-rata per bulan. Antibiotik dikatakan memiliki kategori persediaan normal apabila sisa obat tidak kurang dari pemakaian rata-rata per bulan dan tidak lebih dari tiga kali pemakaian ratarata per bulan.

\section{HASIL DAN PEMBAHASAN}

Dari data pengeluaran antibiotik pada periode bulan Januari-Desember 2017 dan Januari-Desember 2018 didapatkan 152 antibiotik yang memenuhi kriteria inklusi dan 65 antibiotik tidak memenuhi kriteria inklusi karena hanya ada di salah satu yaitu tahun 2017 atau 2018 saja sehingga tidak dapat dilakukan komparasi (Tabel I).

\section{Perhitungan Pengendalian Persediaan Antibiotik dengan Metode EOQ}

Hasil penelitian pada tabel II menunjukkan biaya yang dikeluarkan akibat adanya penyimpanan dan biaya pemesanan obat di gudang. Total biaya yang dikeluarkan untuk biaya penyimpanan pada tahun 2017 yaitu sebesar IDR 516. Biaya penyimpanan 
Tabel I. Total Antibiotik dan Bentuk Sediaan Antibiotik di Instalasi Farmasi Rumah Sakit Tipe A pada Tahun 2017-2018

\begin{tabular}{cc}
\hline Total Jenis Antibiotik & Bentuk Sediaan \\
\hline 217 jenis antibiotik & Tablet, kapsul, kaplet, sirup, injeksi, \\
-152 jenis masuk kriteria inklusi & suppositoria, salep dan obat tetes \\
-65 jenis antibiotik masuk kriteria eksklusi & \\
\hline
\end{tabular}

Tabel II. Biaya Penyimpanan dan Biaya Pemesanan per Unit Barang di Instalasi Farmasi Rumah Sakit Tipe A pada Tahun 2017-2018

\begin{tabular}{cc}
\hline Jenis Biaya & Biaya (IDR)/Unit/Tahun \\
\hline Biaya Penyimpanan & 516 \\
Biaya Pemesanan & 30.209 \\
\hline
\end{tabular}

yang dihasilkan pada penelitian ini lebih tinggi bila dibandingkan dengan penelitian lain di RSUD Cicalengka yaitu IDR 0,5-1457. Bila dibandingkan dengan penelitian lain di Rumah Sakit Paru Jember, biaya penyimpanan yang dihasilkan lebih tinggi yaitu IDR $48.729^{8}$. Perbedaan pada kedua penelitian tersebut dapat disebabkan karena perbedaan tipe rumah sakit sehingga kebutuhan obat di setiap rumah sakit berbeda. Selain itu, hal yang menyebabkan perbedaan biaya penyimpanan yaitu harga setiap obat dan biaya persediaan di rumah sakit. Semakin besar harga obat maka biaya penyimpanan juga akan semakin besar begitu juga sebaliknya9 .

Total biaya pemesanan yang dikeluarkan adalah IDR 30.209 untuk setiap kali pemesanan. Hasil biaya pemesanan yang dilakukan di Rumah Sakit Paru Jember memiliki biaya yang sedikit lebih rendah yaitu IDR 29.3558. Hal ini dapat disebabkan karena pada penelitian tersebut memperhitungkan biaya kertas, tinta printer dan telepon sedangkan pada penelitian ini biaya pemesanan memperhitungkan biaya kertas, telepon, internet, tinta printer dan biaya sumber daya manusia sehingga memberikan hasil yang lebih besar. Pada penelitian lain yang dilakukan di RSUD Cicalengka, biaya pemesanan yang dihasilkan yaitu IDR 94.2917. Salah satu hal yang menyebabkan adanya perbedaan biaya pemesanan adalah jumlah obat dan frekuensi pemesanan yang diperhitungkan tidak sama sehingga memberi hasil yang berbeda. Hal ini sesuai dengan teori dimana biaya pemesanan per periode didapatkan dari frekuensi pesanan dikalikan dengan biaya setiap kali pesan ${ }^{10}$. Selain itu, perbedaan rumah sakit akan mempengaruhi biaya pemesanan yang dilakukan karena jumlah obat yang digunakan di setiap rumah sakit pasti berbeda.

Berdasarkan hasil perhitungan biaya penyimpanan dan biaya pemesanan maka dapat dilakukan perhitungan pengendalian persediaan pada tahun 2017 dan 2018 dengan metode EOQ. Metode EOQ adalah metode yang digunakan untuk menentukan jumlah pesanan yang ekonomis setiap kali dilakukan pemesanan ${ }^{8}$. Metode ini memperhitungkan biaya penyimpanan, jumlah kebutuhan antibiotik dan biaya pemesanan. Data yang digunakan adalah data pengeluaran antibiotik pada tahun 2017 dan 2018 sebagai demand untuk melihat hasil perhitungan pengendalian persediaan antibiotik dengan metode EOQ. Dalam penelitian ini, biaya pemesanan dan biaya penyimpanan dianggap sama setiap antibiotik sehingga hasil EOQ yang berbeda-beda dipengaruhi oleh jumlah kebutuhan antibiotik (D) yang tidak sama setiap antibiotik.

Pada tabel III dapat dilihat perhitungan pengendalian persediaan antibiotik dengan metode EOQ pada tahun 2017 dan 2018 dimana data hanya ditampilkan 5 antibiotik dengan EOQ terbesar dari total keseluruhan antibiotik. Antibiotik dengan EOQ terbesar 
Tabel III. Hasil Perhitungan Pengendalian Persediaan Antibiotik di Instalasi Farmasi Rumah Sakit Tipe A pada Tahun 2017 dan 2018 dengan metode EOQ ${ }^{*}$

\begin{tabular}{clcccc}
\hline Tahun & \multicolumn{1}{c}{$\begin{array}{c}\text { Nama Sediaan } \\
\text { Antibiotik }\end{array}$} & $\begin{array}{c}\text { Jumlah } \\
\text { Pengeluaran } \\
\text { 1 tahun (D) }\end{array}$ & $\begin{array}{c}\text { Biaya } \\
\text { Penyimpanan } \\
\text { (H) }\end{array}$ & $\begin{array}{c}\text { Biaya } \\
\text { Pemesanan } \\
\text { (S) }\end{array}$ & $\begin{array}{c}\text { EOQ } \\
\text { (unit) }\end{array}$ \\
\hline \multirow{4}{*}{ Tahun } & Seftriakson 1 gram Inj & 97.387 & 516 & 30.209 & 3.377 \\
$\mathbf{2 0 1 7}$ & Metronidazol 500 mg & 68.800 & 516 & 30.209 & 2.838 \\
& Sefiksim 100 mg & 68.000 & 516 & 30.209 & 2.822 \\
& Framisetin Sulfat & 60.590 & 516 & 30.209 & 2.644 \\
& Siprofloksasin 500 mg & 37.400 & 516 & 30.209 & 2.093 \\
& Total & $\mathbf{3 3 2 . 1 7 7}$ & & & $\mathbf{1 3 . 7 7 4}$ \\
& Framisetin Sulfat & 89.580 & 516 & 30.209 & 3.239 \\
& Sefiksim 100 mg kapsul & 82.005 & 516 & 30.209 & 3.099 \\
Tahun & Seftriakson 1 g Inj & 62.064 & 516 & 30.209 & 2.696 \\
$\mathbf{2 0 1 8}$ & Amoksisilin 500 mg & 39.200 & 516 & 30.209 & 2.142 \\
& Amoksisilin 500 mg & 37.100 & 516 & 30.209 & 2.084 \\
& kaplet & & & & $\mathbf{1 3 . 2 6 0}$ \\
\hline
\end{tabular}

pada tahun 2017 adalah seftriakson 1 gram injeksi dengan kuantitas pemesanan 3.377 unit sedangkan antibiotik dengan EOQ terendah adalah siprofloksasin $500 \mathrm{mg}$ dengan kuantitas pemesanan 2.093 unit sedangkan pada tahun 2018 antibiotik dengan EOQ terbesar adalah framisetin sulfat dengan kuantitas pemesanan 3.239 dan antibiotik dengan EOQ terendah adalah amoksisilin 500 mg kaplet dengan kuantitas pemesanan 2.084 unit. Jumlah perhitungan pengendalian persediaan 5 antibiotik dengan metode EOQ pada tahun 2017 adalah 13.774 unit sedangkan pada tahun 2018 berjumlah 13.260 unit antibiotik. Hasil EOQ yang berbeda dipengaruhi oleh jumlah kebutuhan antibiotik yang berbeda pada tahun 2017 dan 2018. Semakin besar jumlah pengeluaran antibiotik, maka EOQ yang dihasilkan juga semakin besar. Perbedaan EOQ yang dihasilkan sejalan dengan penelitian di RSUD Cicalengka dimana setiap antibiotik memberikan hasil EOQ yang berbeda ${ }^{7}$. Selain itu, penelitian di Rumah Sakit Meilia memberi hasil EOQ yang berbeda untuk setiap obat ${ }^{11}$. Pada penelitian di Rumah Sakit PKU Aisyiyah Boyolali juga menghasilkan perbedaan EOQ pada setiap obat yang dihitung ${ }^{12}$. Hal ini disebabkan karena adanya perbedaan jumlah kebutuhan obat, biaya penyimpanan dan biaya pemesanan yang berbeda-beda setiap rumah sakit. Namun dengan metode EOQ maka jumlah pesanan dan biaya persediaan dapat berkurang7. Selain itu, metode EOQ dapat digunakan untuk mengurangi kemungkinan adanya obat yang kadaluarsa ${ }^{13}$ serta dapat meminimalkan biaya penyimpanan serta stok yang berlebihan ${ }^{14}$.

\section{Perhitungan Pengendalian Persediaan Antibiotik dengan Metode MMSL}

Metode MMSL digunakan untuk mengatur jadwal pengadaan yang memberikan interval waktu pemesanan untuk menentukan jumlah stok minimum dan maksimum yang sesuai untuk persediaan obat agar tidak terjadi kekosongan maupun kelebihan obat ${ }^{15}$. Berdasarkan data yang didapatkan dengan wawancara kepala gudang Instalasi Farmasi di rumah sakit, lead time yang digunakan adalah 14 hari atau 0,5 bulan. Lead time adalah jarak waktu tunggu dari awal pemesanan sampai obat datang dan siap digunakan ${ }^{16}$. Bila lead time yang digunakan tidak menentu maka dapat meningkatkan safety stock ${ }^{17}$. Lead time sangat penting karena berhubungan dengan penentuan waktu pemesanan yang dilakukan 
Tabel IV. Hasil Perhitungan Pengendalian Persediaan Antibiotik di Instalasi Farmasi Rumah Sakit Tipe A pada Tahun 2017 dan 2018 dengan metode MMSL

\begin{tabular}{clccccc}
\hline Tahun & \multicolumn{1}{c}{$\begin{array}{c}\text { Nama Sediaan } \\
\text { Antibiotik }\end{array}$} & $\begin{array}{c}\text { Safety } \\
\text { Stock } \\
\text { (unit) }\end{array}$ & $\begin{array}{c}\text { Pengeluaran } \\
\text { Rata-rata per } \\
\text { bulan (unit) }\end{array}$ & $\begin{array}{c}\text { S }_{\text {min }} \\
\text { (unit) }\end{array}$ & $\begin{array}{c}\text { S }_{\max } \\
\text { (unit) }\end{array}$ & $\begin{array}{c}\text { Jumlah } \\
\text { Pesan }\end{array}$ \\
\hline \multirow{5}{*}{ Tahun } & Seftriakson 1 gram Inj & 4.058 & 8.115 & 8.115 & 32.462 & 24.347 \\
& Metronidazol 500 mg & 2.867 & 5.733 & 5.733 & 22.933 & 17.200 \\
& Sefiksim 100 mg & 2.833 & 5.667 & 5.667 & 22.667 & 17.000 \\
& Framisetin Sulfat & 2.525 & 5.049 & 5.049 & 20.197 & 15.148 \\
& Siprofloksasin 500 mg & 1.558 & 3.117 & 3.117 & 12.467 & 9.350 \\
& Total & $\mathbf{1 3 . 8 4 1}$ & $\mathbf{2 7 . 7 2 1}$ & $\mathbf{2 7 . 7 2 1}$ & $\mathbf{1 1 0 . 7 2 6}$ & $\mathbf{8 3 . 0 4 5}$ \\
& Framisetin Sulfat & 3.733 & 7.465 & 7.465 & 29.860 & 22.395 \\
& Sefiksim 100 mg kapsul & 3.417 & 6.834 & 6.834 & 27.335 & 20.501 \\
\multirow{2}{*}{ Tahun } & Seftriakson 1 g Inj & 2.586 & 5.172 & 5.172 & 20.668 & 15.516 \\
& Amoksisilin 500 mg & 1.633 & 3.267 & 3.267 & 13.067 & 9.800 \\
& Amoksisilin 500 mg & 1.545 & 3.092 & 3.092 & 12.367 & 9.275 \\
& kaplet & & & & & \\
& Total & $\mathbf{1 2 . 9 1 4}$ & $\mathbf{2 5 . 8 3 0}$ & $\mathbf{2 5 . 8 3 0}$ & $\mathbf{1 0 3 . 2 9 7}$ & $\mathbf{7 7 . 4 8 7}$ \\
\hline
\end{tabular}

kembali18. Safety stock atau stok pengaman adalah persediaan yang dilakukan untuk mengantisipasi ketidakpastian permintaan dan persediaan ${ }^{19}$. Safety stock didapatkan dengan memperhitungkan lead time dan pemakaian rata-rata tiap antibiotik. Stok minimum didapatkan dari rata-rata pemakaian dikalikan dengan lead time ditambahkan dengan stok pengaman. Stok maksimum dapat ditentukan dari jumlah stok minimum ditambahkan dengan periode pengadaan dikalikan dengan rata-rata pemakaian ${ }^{2}$. Periode pengadaan yang terjadwal ditetapkan setiap 3 bulan sekali. Periode pengadaan dan lead time untuk setiap jenis antibiotik dianggap sama.

Hasil penelitian pada tabel IV menunjukkan perhitungan pengendalian persediaan antibiotik tahun 2017 dan tahun 2018 dengan metode MMSL. Sama dengan metode EOQ, pada metode MMSL data ditampilkan 5 antibiotik dengan jumlah pesan terbesar. Antibiotik dengan jumlah pesan terbesar pada tahun 2017 adalah seftriakson 1 gram injeksi dengan jumlah pemesanan 24.347 unit sedangkan antibiotik dengan jumlah pesan terendah adalah siprofloksasin $500 \mathrm{mg}$ dengan jumlah pemesanan 9.350 unit sedangkan pada tahun 2018 antibiotik dengan MMSL terbesar adalah framisetin sulfat dengan jumlah pemesanan 22.395 dan antibiotik dengan MMSL terendah adalah amoksisilin $500 \mathrm{mg}$ kaplet dengan jumlah pemesanan 9.275 unit. Jumlah perhitungan pengendalian persediaan 5 antibiotik dengan metode MMSL pada tahun 2017 adalah 83.045 unit sedangkan pada tahun 2018 berjumlah 77.487 unit antibiotik.

Penelitian ini sejalan dengan penelitian di Rumah Sakit Islam Surabaya dimana setiap obat menghasilkan jumlah pesanan yang berbeda $^{15}$. Selain itu, penelitian yang dilakukan di RSUP Dr. Sardjito juga memberikan hasil jumlah pesanan yang berbeda meskipun periode pengadaan yang digunakan sama yaitu 3 bulan ${ }^{20}$. Hal ini dapat disebabkan karena jumlah pesanan bergantung juga pada lead time, safety stock dan pengeluaran rata-rata setiap antibiotik. Jumlah pesanan yang harus dilakukan dapat dihitung dengan mengurangi stok maksimum dengan stok minimum. Bila persediaan antibiotik sudah mencapai level minimum maka harus dilakukan pemesanan sebesar jumlah pesan agar tidak terjadi kekurangan stok. Pemesanan kembali dilakukan saat stok 
Tabel V. Kategori Persediaan Antibiotik Secara Riil di Rumah Sakit Tipe A pada Tahun 2018, dengan Simulasi Metode EOQ dan MMSL

\begin{tabular}{ccccccc}
\hline $\begin{array}{c}\text { Kategori } \\
\text { Persediaan }\end{array}$ & $\begin{array}{c}\text { Stok Riil } \\
\text { 2018 (unit) }\end{array}$ & $\begin{array}{c}\text { EOQ } \\
\text { (unit) }\end{array}$ & $\begin{array}{c}\text { Ab pada Stok } \\
\text { Riil dan EOQ } \\
\text { (\%) }\end{array}$ & $\begin{array}{c}\text { MMSL } \\
\text { (unit) }\end{array}$ & $\begin{array}{c}\text { Ab Riil } \\
\text { dan } \\
\text { MMSL (\%) }\end{array}$ & $\begin{array}{c}\text { Ab pada } \\
\text { EOQ dan } \\
\text { MMSL (\%) }\end{array}$ \\
\hline Stagnant & $36(23,68 \%)$ & $\begin{array}{c}68 \\
(44,73 \%)\end{array}$ & $20(13,15 \%)$ & $\begin{array}{c}73 \\
(48,02 \%)\end{array}$ & $22(14,47 \%)$ & $39(25,65 \%)$ \\
Stockout & $84(55,26 \%)$ & $\begin{array}{c}58 \\
(38,15 \%)\end{array}$ & $34(22,36 \%)$ & $\begin{array}{c}65 \\
(42,76 \%)\end{array}$ & $34(22,7 \%)$ & $35(23,02 \%)$ \\
Normal & $32(21,05 \%)$ & $\begin{array}{c}26 \\
(17,10 \%)\end{array}$ & $10(6,57 \%)$ & $\begin{array}{c}14 \\
(9,21 \%)\end{array}$ & $2(1,32 \%)$ & $4(2,63 \%)$ \\
Total & 152 & 152 & 64 & 152 & 58 & 78 \\
\hline
\end{tabular}

mencapai level minimum karena stok minimum disediakan saat masa tenggang waktu (lead time) $)^{15}$.

\section{Kategori Persediaan Antibiotik}

Kategori persediaan antibiotik baik pada metode EOQ maupun metode MMSL ada 3 yaitu stagnant, stockout dan normal. Antibiotik dikatakan stagnant bila sisa stok lebih dari tiga kali pemakaian rata-rata per bulan sedangkan antibiotik yang dikatakan stockout bila sisa stok kurang dari pemakaian rata-rata per bulan'. Antibiotik dikatakan memiliki kategori persediaan normal apabila sisa obat tidak kurang dari pemakaian ratarata per bulan dan tidak lebih dari tiga kali pemakaian rata-rata per bulan.

Dalam menentukan kategori persediaan antibiotik dengan metode EOQ maka diperlukan data stok awal dan pembelian serta perhitungan frekuensi pembelian dan Consumption Average (CA). Stok awal didapatkan dari stok awal pada bulan Januari 2018 sedangkan pembelian EOQ didapatkan dari data pengendalian persediaan dengan metode EOQ pada tahun 2017. Dengan menggunakan data pengendalian persediaan pada tahun 2017, maka dapat dilihat kategori persediaan mana yang memberi hasil lebih baik antara riil 2018 atau dengan menggunakan metode EOQ. Frekuensi pembelian dapat ditentukan dari pemakaian per tahun dibagi dengan pembelian EOQ sedangkan pemakaian per tahun sendiri adalah jumlah pemakaian antibiotik dalam setahun. CA adalah pemakaian rata-rata per bulan yang didapat dari pemakaian per tahun dibagi 12 bulan sedangkan 3xCA adalah 3 kali pemakaian rata-rata per bulan. Sisa stok didapatkan dari pembelian EOQ dikali dengan frekuensi pembelian kemudian ditambah stok awal dan dikurangi dengan pemakaian per tahun.

Pada metode MMSL, stok awal sama dengan metode EOQ yaitu stok awal pada bulan Januari 2018. Pembelian MMSL didapatkan dari data pengendalian persediaan dengan metode EOQ dan MMSL pada tahun 2017. Dengan menggunakan data pengendalian persediaan pada tahun 2017, maka dapat dilihat kategori persediaan mana yang memberi hasil lebih baik antara riil 2018 atau dengan menggunakan metode MMSL. Frekuensi pembelian dapat ditentukan dari periode pengadaan, karena periode pengadaan dalam setahun adalah setiap 3 bulan sekali maka frekuensi pembeliannya yaitu 4 kali tiap tahun. Untuk cara perhitungan $\mathrm{CA}$ dan $3 \times \mathrm{CA}$ pada metode MMSL sama dengan metode EOQ. Perhitungan sisa stok didapatkan dari pembelian MMSL dikali dengan frekuensi pembelian kemudian ditambah stok awal dan dikurangi dengan pemakaian per tahun.

Dari hasil kategori persediaan yang telah dihitung dengan metode EOQ dan MMSL, maka ditentukan kategori persediaan antibiotik yang dibandingkan dengan keadaan riil pada tahun 2018. Hasil penelitian pada tabel $\mathrm{V}$ menunjukkan kategori 
persediaan antibiotik data riil pada tahun 2018, dengan metode EOQ dan dengan metode MMSL. Dari tabel tersebut dapat dilihat bahwa dengan perencanaan konsumsi tahun 2018, antibiotik yang masuk kategori stagnant yaitu 36 (23,68\%) sedangkan jumlah antibiotik stockout yaitu $84 \quad(55,26 \%)$ dan antibiotik stok normal yaitu sebesar 32 $(21,05 \%)$ jenis antibiotik. Dengan metode pengendalian EOQ, jumlah antibiotik stagnant meningkat yaitu sebanyak 68 antibiotik $(44,73 \%)$ namun jumlah antibiotik yang stockout menurun yaitu $58(38,15 \%)$ dan antibiotik stok normal yaitu $26(17,10 \%)$ jenis antibiotik. Dari tabel V juga dapat dilihat bahwa terdapat 20 jenis antibiotik stagnant, 34 jenis antibiotik stockout dan 10 jenis antibiotik normal yang sama baik pada data riil 2018 maupun dengan metode EOQ.

Dengan metode pengendalian MMSL, jumlah antibiotik yang stagnant meningkat yaitu sebanyak $73(48,02 \%)$, antibiotik stockout menurun yaitu $65(42,76 \%)$ dan antibiotik normal juga menurun menjadi $14(9,21 \%)$ dari keadaan riil pada tahun 2018. Bila dibandingkan dengan keadaan riil 2018, jumlah antibiotik pada simulasi metode MMSL yang memiliki kategori sama adalah sebanyak 58 antibiotik dengan kategori stagnant 22 antibiotik, stockout 34 antibiotik dan normal 2 antibiotik. Pada metode EOQ dan MMSL, terdapat 78 antibiotik yang memiliki kategori sama pada kedua metode dengan jumlah obat stagnant 39 sedangkan obat stockout 25 dan obat yang normal 4. Dari hasil tersebut, diketahui bahwa lebih banyak terdapat obat stagnant dan stockout dibandingkan obat normal pada kedua metode.

Hasil penelitian ini berbeda dengan penelitian di RSU Haji Surabaya dimana jumlah jenis obat stagnant $118(39 \%)$ dan jumlah jenis obat stockout $166 \quad(54 \%)^{22}$. Penelitian juga berbeda dengan penelitian di rumah sakit Mata Masyarakat Jawa Timur dimana hasil penelitian obat stagnant sebesar $39 \%$ dan stockout sebesar $29 \%$ dari total 1.033 jenis obat ${ }^{4}$. Hal ini menunjukkan perbedaan rumah sakit dapat menyebabkan hasil jumlah obat stagnant dan stockout yang sangat berbeda. Faktor lain yang dapat menyebabkan adanya perbedaan stagnant dan stockout adalah adanya ketidaksesuaian antara jumlah stok dengan pengeluaran antibiotik setiap bulannya ${ }^{5}$. Pada keadaan stockout, proses yang terjadi di rumah sakit akan terhambat dan dapat berdampak buruk terhadap pengobatan pasien. Selain itu, banyaknya obat yang stockout dapat menyebabkan mutu pelayanan rumah sakit menurun bila terdapat resep yang tidak dilayani ${ }^{21}$. Obat yang mengalami stagnant memiliki risiko kadaluarsa dan kerusakan yang tinggi bila tidak disimpan dengan benar*.

Berdasarkan hasil penelitian tabel $\mathrm{V}$ dapat dilihat bahwa metode EOQ dapat menurunkan antibiotik yang stockout lebih banyak daripada metode MMSL seperti pada penelitian di Gudang Farmasi Klinik XYZ dimana metode EOQ dapat mengoptimalkan persediaan serta menurunkan total biaya persediaan ${ }^{22}$. Hal ini sesuai dengan penelitian lainnya dimana metode EOQ dapat menurunkan efisiensi biaya persediaan dalam pemesanan obat ${ }^{23}$.

Faktor yang dapat menyebabkan terjadinya antibiotik yang stagnant adalah adanya pengadaan yang melebihi jumlah pemakaian antibiotik ${ }^{24}$. Hal yang mempengaruhi terjadinya stockout adalah penggunaan antibiotik yang meningkat dibandingkan periode sebelumnya. Faktor lain yang dapat mempengaruhi adanya stockout adalah jumlah perencanaan yang tidak sesuai dengan pemakaian obat, dan lead time tidak sesuai prediksi ${ }^{25}$. Banyaknya antibiotik yang stagnant menunjukkan perlunya pengurangan perencanaan pada periode selanjutnya agar tidak terjadi kelebihan stok. Begitu juga sebaliknya, banyaknya antibiotik yang stockout menunjukkan perlunya diadakan perencanaan yang lebih banyak untuk periode selanjutnya agar tidak terjadi kekurangan stok.

Kerugian akibat obat yang stagnant dalam segi biaya yaitu biaya pembelian, biaya pemesanan, biaya penyimpanan dan biaya 
kerusakan atau kadaluarsa. Kerugian yang akan ditanggung akibat banyaknya obat yang stockout adalah hilangnya opportunity cost atau biaya kesempatan 4 . Untuk melihat kerugian akibat terjadinya obat stagnant dan stockout dalam segi biaya dapat memperhitungkan opportunity cost dan opportunity loss yang terjadi.

Penentuan jumlah pemesanan dan perencanaan pembelian sangat penting untuk pengendalian persediaan antibiotik sehingga diperlukan jumlah pemesanan yang optimal untuk mengantisipasi adanya fluktuasi permintaan maupun kekosongan stok obat ${ }^{26}$. Dengan adanya perencanaan yang baik maka dapat menghindari terjadinya masalah dalam pelayanan kefarmasian serta menunjang pelayanan kesehatan di rumah sakit. Keterbatasan dalam penelitian ini yaitu tidak didapatkan biaya penyimpanan dan biaya pemesanan secara rinci dan lengkap.

\section{KESIMPULAN}

Jumlah pemesanan yang harus dilakukan agar stok antibiotik optimal dengan metode EOQ memberikan hasil yang lebih rendah sedangkan jumlah pemesanan dengan metode MMSL lebih besar. Pada keadaan riil 2018, jumlah antibiotik yang masuk kategori stagnant lebih rendah dibanding dengan metode EOQ dan MMSL, namun jumlah antibiotik stockout dengan metode EOQ dan MMSL lebih rendah daripada keadaan riil 2018 dan antibiotik stok normal dengan metode EOQ lebih tinggi dibandingkan metode MMSL. Evaluasi perencanaan dengan menggunakan metode pengendalian persediaan EOQ dapat menurunkan jumlah antibiotik stockout lebih banyak daripada metode MMSL.

\section{UCAPAN TERIMA KASIH}

Terimakasih kepada Direktur Rumah Sakit yang telah memberikan ijin penelitian.

\section{DAFTAR PUSTAKA}

1. Peraturan Menteri Kesehatan RI no 72. Standar Pelayanan Kefarmasian di Rumah Sakit. 2016, Jakarta : Menteri Kesehatan RI.
2. Kusnadi, S.A., Manajemen Obat di Rumah Sakit, Yogyakarta: Fakultas Farmasi Universitas Gajah Mada;2015.

3. Rosmania F.A., dan Supriyanto S. Analisis Pengelolaan Obat sebagai Dasar Pengendalian Safety Stock pada Stagnant dan Stockout Obat. Jurnal Administrasi Kesehatan Indonesia. 2015;3:1-10.

4. Hadidah, I.S. dan Rochmah, T.N. Faktor Penyebab Kejadian Stagnant dan Stockout di Instalasi Farmasi UPT Rumah Sakit Mata Masyarakat Jawa Timur, Jurnal Manajemen Kesehatan Yayasan RS Dr. Soetomo. 2016;2:110-117.

5. Mumek, V.M., Citraningtyas G., dan Yamlean P.V.Y. Evaluasi Perencanaan dan Pengadaan Obat di Instalasi Farmasi RSUP Prof. Dr. R. D. Kandou Manado Berdasarkan Analisis ABCVEN, Pharmacon Jurnal Ilmiah FarmasiUnsrat. 2016; 5.

6. Dampung, V.M., Maidin A., dan Mardiana R.Y. Penerapan Metode Konsumsi dengan Peramalan EOQ, MMSL, dan Analisis ABC-VEN dalam Manajemen Perbekalan Farmasi di Rumah Sakit Pelamonia Makassar, Media Farmasi. 2018; 14(1):97-104

7. Kencana, G.G. Analisis Perencanaan dan Pengendalian Persediaan Obat Antibiotik di RSUD Cicalengka Tahun 2014. Jurnal Administrasi Rumah Sakit. 2016;3:42-52.

8. Irlyna, A.R., Witcahyo, E. dan Sandra, C. Perhitungan Obat dengan Metode Economic Order Quantity dan Reorder Point di Instalasi Farmasi Rumah Sakit Paru Jember. Artikel Ilmiah Hasil Penelitian Mahasiswa. 2016;3(2):1-5.

9. Ercis, Satibi, dan Widodo, G.P. Analisis Pengendalian Obat Sitostatika dengan Metode EOQ dan ROP. Jurnal Manajemen dan Pelayanan Farmasi. 2013; 3(3):203-210.

10. Seto, S., Nita, Y., dan Triana, L. Manajemen Farmasi Lingkup : Apotek, Farmasi Rumah Sakit, Industri Farmasi Pedagang Besar Farmasi. Edisi Keempat, 
Surabaya:.Airlangga University Press; 2015.

11. Octaviany, M. Analisis Pengendalian Persediaan Obat Antibiotik di RS Meilia pada Tahun 2014 dengan Menggunakan Metode Analisis ABC Indeks Kritis. Jurnal Administrasi Rumah Sakit. 2018; 4(2):75-88.

12. Listyorini, P.I. Perencanaan dan Pengendalian Obat Generik dengan Metode Analisis ABC, EOQ dan ROP (Studi Kasus Di Unit Gudang Farmasi RS PKU 'Aisyiyah Boyolali). Jurnal Ilmiah Rekam Medis dan Informatika Kesehatan, 2016; 6(2): 19-25.

13. Alfanda, D., Pujotomo D. dan Nugroho. S.W.P. Pengendalian Obat dengan Menggunakan Economic Order Quantity (EOQ) Probabilitas Berdasarkan Analisis ABC dengan Mempertimbangkan Masa Kadaluwarsa dan Pengembalian Produk. Industrial Engineering Online Journal, 2018; 7: 3.

14. Nisa, A.F. Analisis Pengendalian Persediaan $\mathrm{Ob}$ at Berdasarkan Metode ABC, EOQ dan ROP (Studi Kasus pada Gudang Farmasi Rumah Sakit Universitas Muhammadiyah Gresik). Jurnal Manajerial, 2019; 6(1): 17-24.

15. umalasari, A. dan Rochmah T.N. Pengendalian Persediaan Obat Generik dengan Metode MMSL (MinimumMaximum Stock Level) di Unit Farmasi Rumah Sakit Islam Surabaya. Jurnal Manajemen Kesehatan STIKES Yayasan Rs.Dr.Soetomo. 2016; 2:143-152.

16. Sofyan, D.K. Perencanaan dan Pengendalian Produksi. Yogyakarta: Graha Ilmu; 2013.

17. Dyatmika, S.B. Pengendalian Persediaan Obat Generik dengan Metode Analisis ABC, Metode Economic Order Quantity (EOQ), dan Reorder Point (ROP) di Apotek XYZ Tahun 2017. Jurnal Modus. 2018; 30 (1): 71-95.

18. Wardhani, P.W. Perencanaan dan
Pengendalian Persediaan dengan Metode EOQ. Jurnal Media Mahardika. 2015, 3(3): 310-328.

19. Ristono, A. Manajemen Persediaan. Yogyakarta: Graha Ilmu; 2013.

20. Indarti, T.R., Satibi dan Yuniarti E. Pengendalian Persediaan Obat dengan Minimum-Maximum Stock Level di Instalasi Farmasi RSUP Dr. Sardjito Yogyakarta. Jurnal Manajemen dan Pelayanan Farmasi.2019; 9(3): 192-106.

21. Sheina B., Umam MR. Penyimpanan Obat Di Gudang Instalasi Farmasi RS PKU Muhammadiyah Yogyakarta Unit I. J Kes Mas UAD ISSN 1978-0575. 2010;4(1):1-75.

22. Buwono, R.I., Priyandari Y. dan Jauhari W.A. Usulan Perencanaan dan Pengendalian Persediaan Obat pada Gudang Farmasi Klinik XYZ dengan Menggunakan Metode EOQ. Jurnal Performa. 2014; 13(1): 29-40.

23. Hartih, N.A., Satibi dan Widodo G.P. Penerapan Metode Economic Order Quantity dan Reorder Point dalam Meningkatkan Efisiensi Persediaan Obat Reguler di Instalasi Farmasi Rumah Sakit. Jurnal Manajemen dan Pelayanan Farmasi, 2013; 3(4): 249-254.

24. Mellen, R.C. dan Pudjirahardjo, W.J. Faktor Penyebab dan Kerugian Akibat Stockout dan Stagnant Obat di Unit Logistik RSU Haji Surabaya. Jurnal Administrasi Kesehatan Indonesia. 2013;1:99-107.

25. Fairuz, N.A., dan Yustiawan T. Perhitungan Konsumsi Obat Untuk Logistik Medik di Rumah Sakit Islam Jemursari Surabaya. Jurnal Administrasi Kesehatan Indonesia. 2017; 5(2):155-161.

26. Suryantini, N.L., Citranintyas G. dan Sudewi S. Evaluasi Perencanaan dan Pengadaan Obat Antibiotik dengan Menggunakan Analisis ABC terhadap Nilai Persediaan di Instalasi Farmasi RSUP Prof. Dr. R. D. Kandou Manado. Pharmacon Jurnal Ilmiah Farmasi, 2016; 5(3): 12-22. 